\title{
USO DE FITORREGULADORES SINTÉTICOS IN VITRO
}

\author{
LIMA, Ângela Simone Freitag ${ }^{1}$ \\ GONÇALVES, José Leonardo Moraes \\ GONÇALVES, Antonio Natal
}

\begin{abstract}
Recebido em: 2018.10.22 Aprovado em: 2019.03.26 $\quad$ ISSUE DOI: $10.3738 / 1982.2278 .3501$
RESUMO: O presente estudo teve por objetivo avaliar a emissão da brotação de Corymbia citriodora in vitro sob influência de diferentes citocininas sintéticas (BAP, TDZ, Tiouréia e Actara) com função de regulador em meio de cultura JADS, avaliando qual ou quais serão mais eficientes na indução da brotação. Cada tratamento foi composto por três repetições com quatro explantes por repetição. Foram feitas duas avaliações, uma na data de implantação e a segunda após 45 dias. Concluiu-se que para indução de calos, é recomendável a adição tanto de BAP quanto de TDZ, nas dosagens de 2.2 e $4.4 \mu \mathrm{mol} . \mathrm{L}^{-1}$ no meio de cultura por apresentar maior TCR (taxa de crescimento relativo) e maiores valores médios de peso fresco e seco. Para o alongamento e posterior enraizamento com produção de mudas, recomenda-se o uso tanto de actara quanto de tiouréia por apresentarem maior percentual de matéria seca e por inibir a calogênese.
\end{abstract}

Palavras-chave: Citocinina. Brotação. Calogênese. Fisiologia. Corymbia citriodora.

\section{USE OF SYNTHETIC FITORREGULATORS IN VITRO}

SUMMARY: This study aimed to evaluate the issue of budding Corymbia citriodora in vitro under the influence of different synthetic cytokinins (BAP, TDZ, Thiourea and Actara) with regulatory function in the midst of JADS culture, evaluating which one or ones will be most effective in inducing sprouting. Each treatment consisted of three replications with four explants per repetition. There were two assessments, the implementation date and the second after 45 days. It was concluded that for callus induction, it is advisable to add both BAP as TDZ, at doses of 2.2 and $4.4 \mu \mathrm{mol} . \mathrm{L}-1$ in the culture medium due to its higher RGR (relative growth rate) values and higher average wet weight and dry. For stretching and later with rooting seedling production, we recommend the use of both Actara as of thiourea by the fact that they have a higher percentage of dry matter and to inhibit callus formation.

Keywords: Citokininas. Budding. Calogênese. Physiology. Corymbia citriodora.

\section{INTRODUÇÃO}

O crescimento ou não de uma gema é uma resposta à combinação de fatores relativos ao ambiente (ecodormência), à influência de outro órgão do vegetal (paradormência) ou a eventos bioquímicos e fisiológicos que acontecem no interior da gema (endodormência) (CARVALHO et al., 2010).

Reguladores vegetais são substâncias sintéticas que aplicadas exogenamente possuem ações similares aos grupos de hormônios vegetais conhecidos (auxinas, giberelinas, citocininas, retardadores, inibidores e etileno) (DAVIES, 2004). Os reguladores vegetais podem atuar diretamente nas diferentes estruturas celulares e nelas provocar alterações físicas, químicas e metabólicas (CASTRO; VIEIRA, 2001). Sua função é transportar informações e coordenar o desenvolvimento vegetal (HINOJOSA, 2000).

\footnotetext{
${ }^{1}$ Universidade de São Paulo - Escola Superior de Agricultura "Luiz de Queiroz" (USP/ESALQ)
} 
Alguns estudos tiveram resultados razoáveis com a micropropagação da espécie, em que houve pequeno crescimento e baixa proliferação de gemas axilares (ASSIS et al., 1993; HUANG et al., 1993). Segundo Caldas et al. (1990), a composição e concentração hormonais no meio são fatores determinantes do crescimento e do padrão de desenvolvimento da maioria dos sistemas da cultura de tecidos. Dentre os reguladores de crescimento, as citocininas são substâncias que estão diretamente relacionadas com a divisão celular.

As citocininas podem promover o transporte de nutrientes para as folhas a partir de outros órgãos vegetativos, fenômeno esse conhecido como "mobilização de nutrientes induzida por citocinina". Experimentos demonstraram que os nutrientes são preferencialmente transportados e acumulados em tecidos tratados com citocininas, sendo sugerido que o hormônio estimula a mobilização de nutrientes, originando uma nova relação de fonte-dreno (TAIZ; ZEIGER, 2009).

$\mathrm{Na}$ cultura de ápices caulinares, os reguladores são utilizados principalmente para a proliferação de gemas axilares, através da capacidade de modificação da dominância apical (BHOJWANI; RAZDAN, 1996). De acordo com Phillips (1969), Leopold e Kriedmann (1975) citados por Ribeiro et al. (1987), a rápida diferenciação e desenvolvimento das gemas que se encontram nas cepas, pode ser relacionado com o elevado nível de citocinina que se acumula após o corte. Ao surgir a brotação, a citocinina exerce ainda a função de carreador de nutrientes e outros hormônios para o ápice da planta.

Uma citocinina que está sendo atualmente estudada é a tiouréia. A tiouréia pode ser encontrada pelo nome de thiourea, POLO 500 SC, apresentado quimicamente por 1-tert-butyl-3(2,6-di-isopropyl-4-phenoxiphenyl) thiourea (Diafentiurom) com $500 \mathrm{~g} / \mathrm{L} \quad(50 \% \mathrm{~m} / \mathrm{v})$ de ingrediente ativo e $545 \mathrm{~g} / \mathrm{L}(54,5 \% \mathrm{~m} / \mathrm{v})$ de ingrediente inerte (ABNT, 2008). São substâncias não-específicas como nitratos, nitritos e derivados de uréia são denominadas como promotoras da germinação (DELATORRE et al., 1997). Porém, quando em altas concentrações, a tiouréia inibe a germinação e o crescimento de plântulas (ADKINS et al., 1984).

Segundo Delatorre et al. (1997), os resultados aqui apresentados indicam que a tiouréia estimula a germinação de sementes de estilosante, principalmente através da produção de etileno. Processo esse, alcançado em período inferior a doze horas. Sabe-se que a tiouréia age sobre a entrada de potássio no eixo embrionário, altera o mecanismo respiratório, atua sobre a remobilização de reservas, abole o requerimento por luz (HERNANDEZ-NISTAL et al., 1983) e interage com ABA (ácido abcísico) reduzindo seus efeitos inibitórios (MAYER; POLJAKOFFMAYBER, 1984). 
A tiouréia parece apresentar também, um efeito semelhante às citocinina, porém há inferências de que a ação se dê via estímulo à síntese de etileno, pelo menos em sementes de Xanthium pensylvanicum (DELATORRE et al., 1997).

Uma das últimas inovações na micropropagação de espécies lenhosas tem sido a introdução do tidiazuron (TDZ) (N-fenil-N'-1,2,3-tiadiazol-5-ylureia) como regulador de crescimento no meio de cultura. Embora tenha sido desenvolvido para ser utilizado como desfoliante para o algodão, com o nome comercial de Dropp, o TDZ possui alta atividade de citocinina em cultivos in vitro, quando utilizado em pequenas concentrações (MOK et al., 1982). A superior potencialidade do TDZ sobre as citocininas do tipo das adeninas, em particular 6 benzilaminopurina e zeatina, ficou comprovada em bioensaios com cultura de calos de Phaseolus (MOK et al., 1980).

O thidiaruzon tem sido utilizado para a multiplicação de gemas axilares de espécies lenhosas durante a micropropagação. Neste sentido, a embriogênese somática de algumas espécies pode ser estimulada com a adição de TDZ. Para Cayratia japonica (Thump.) Gagnep, herbácea perene, a adição de TDZ aumentou até $25 \%$ a formação de embriões somáticos (ZHOU et al., 1994).

A comparação entre o TDZ e o BAP na multiplicação de brotações de Eucalyptus dunnii foi realizada com o objetivo de se obter uma fonte de citocinina alternativa para o estágio da multiplicação, visto que subcultivos contínuos com o BAP podem causar a inibição do enraizamento para várias espécies de Eucalyptus (BENNETT et al., 1992).

A produtividade de um pomar de videira depende, além de outros fatores, da obtenção de alto índice de brotação das gemas. Para se conseguir isto, usualmente, trata-se as gemas com as soluções de calciocianamida a $20 \%$ ou de cianamida hidrogenada (Dormex®) a 4 ou $5 \%$. Os fatores ligados à planta e ao ambiente também têm grandes influências sobre a brotação. Normalmente, as plantas bem supridas de substâncias de reserva brotam melhor do que aquelas debilitadas e sofrem menos com as oscilações climáticas tão frequentes no inverno do Estado do Paraná.

As temperaturas altas pós-tratamento adiantam o início de brotação e as baixas retardam. Sua grande vantagem sobre a calciocianamida é a facilidade no preparo da solução a ser aplicada por pulverização. Este produto contém $63 \%$ de $\mathrm{CaCN}_{2}, 17 \%$ de hidróxido de cálcio e $12 \%$ de carbono livre. O produto em pó, mais usado, tem $22 \%$ de nitrogênio, sendo $98 \%$ deste total solúvel em água (NACHTIGAL; ROBERTO, 2005).

Sendo assim, objetivou-se avaliar a emissão da brotação de $C$. citriodora in vitro sob influência diferentes citocininas sintéticas em meio de cultura JADS, avaliando qual ou quais 
serão mais eficientes levando-se em conta a taxa de crescimento relativo, o percentual de matéria seca e o peso fresco e seco inicial e final.

\section{MATERIAL E MÉTODO}

O estudo foi conduzido no Laboratório de Fisiologia das Árvores localizado no Departamento de Ciências Florestais da Escola Superior de Agricultura "Luiz de Queiroz", campus da Universidade de São Paulo (USP), situado no Município de Piracicaba, Estado de São Paulo, Brasil.

Foram utilizadas brotações de gemas caulinares micropropagadas in vitro de Corymbia citriodora, introduzidas em meio de cultura JADS, na forma sólida com adição dos reguladores nas dosagens pré-estabelecidas. O processo de repicagem para obtenção dos explantes foi efetuado em câmara de fluxo laminar devidamente esterilizada.

O experimento consistiu em um delineamento bloco ao acaso com cinco tratamentos sendo estes: T0 (sem adição de reguladores no meio de cultura); T1 (Adição de BAP no meio de cultura); T2 (Adição de TDZ no meio de cultura); T3 (Adição de Tiouréia no meio de cultura) e T4 (Adição de Actara no meio de cultura), com quatro dosagens (1,1, 2,2, 4,4 e 8,8 $\mu$ mol), por tratamento. Cada tratamento foi composto por três repetições com quatro explantes por repetição.

Foram feitas duas avaliações, uma na data de implantação (dia 0) e a segunda 45 dias após. Nas duas épocas de avaliação verificou-se o PMF (peso de matéria fresca), o PMS (peso de matéria seca) e a TCR (taxa de crescimento relativo), através da retirada de três frascos de cada tratamento para análise. O PMS será obtido após a secagem da matéria fresca dos frascos de cada tratamento em estufa a $60{ }^{\circ} \mathrm{C}$ durante $72 \mathrm{~h}$. Cada frasco com 4 explantes e $40 \mathrm{~mL}$ de meio de cultura sólido (agar).

A análise da taxa de crescimento relativo será definida por meio da equação 1 dada por Hunt (1982).

\section{$\mathbf{T C R}=$}

\section{$\ln \mathrm{PMS}_{2}$ - In $\mathrm{PMS}_{1}$}

$$
\mathbf{T}_{2}-\mathbf{T}_{1}
$$

Onde: $\ln =\operatorname{logaritmo~neperiano;~} \mathrm{PMS}_{2}=$ produção de matéria seca no período final; $\mathrm{PMS}_{1}=$ produção de matéria seca no período inicial; $\quad \mathrm{T}_{2}=$ tempo final; $\mathrm{T}_{1}=$ tempo inicial.

A cultura foi mantida em sala de crescimento com temperatura de $25^{\circ} \mathrm{C} \pm 2{ }^{\circ} \mathrm{C}$, fotoperíodo de 12 horas, com $50 \mu \mathrm{mol} \mathrm{m} \mathrm{m}^{-1}$ de radiação fotossinteticamente ativa (PAR) equivalente a 2000 lux, fornecida por luz branca fria localizada $30 \mathrm{~cm}$ acima do nível de cada 
prateleira, gerada por duas lâmpadas de $110 \mathrm{~W}$ de potência e $250 \mathrm{~cm}$ de comprimento aproximadamente, durante todo o tempo de pesquisa.

Os dados foram submetidos à análise de variância com auxilio do software SAS (SAS INSTITUTE, INC, 1997), adotando-se o intervalo de confiança da média $(\alpha-0,95)$.

\section{RESULTADO E DISCUSSÃO}

A maioria dos trabalhos in vitro utilizam o BAP na dosagem de $1,1 \mu \mathrm{mol}$, como indutor de crescimento. No entanto, através deste trabalho observou-se que tanto o TDZ quanto o BAP promoveram explantes com maior TCR ao se aplicar concentrações de 8,8, 2,2 e 4,4 $\mu$ mol de BAP e TDZ, em explantes de C. citriodora, respectivamente. Tais resultados vão de encontro ao verificado por Mok et al. (1982), onde afirma que o TDZ possui alta atividade de citocinina em cultivos in vitro, quando utilizado em pequenas concentrações.

Os explantes com aplicação dos reguladores tioureia e actara obtiveram as menores TCR, apresentando um desenvolvimento semelhante a testemunha onde não fora aplicado nenhum regulador de crescimento (Figura 1).

FIGURA 01- Taxa de crescimento relativo de $C$. citriodora in vitro, aos quarenta e cinco dias após instalação

FIGURE 01- Rate of relative growth of $C$. citriodora in vitro at forty-five days after installation

\section{Taxa de Crescimento Relativo}

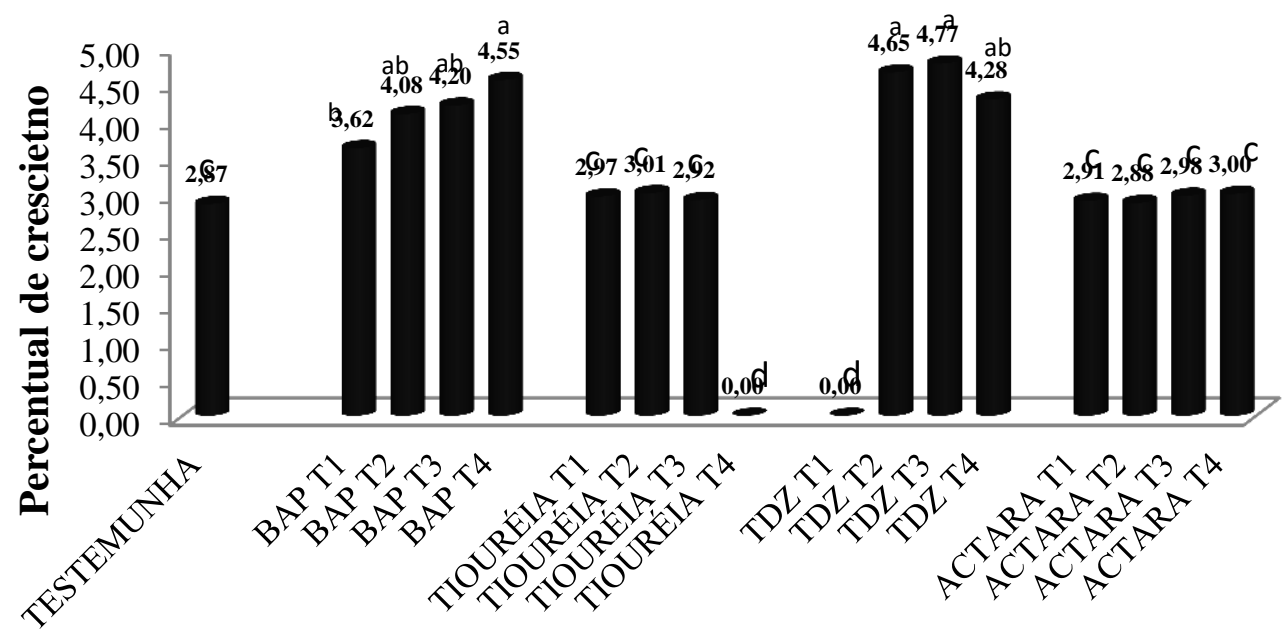

Reguladores Sintéticos avaliados

* T1 (Adição de 1,1 $\mu$ mol de regulador no meio de cultura); T2 (Adição de 2,2 T $\mu$ mol de reguladores no meio de cultura); T3 (Adição de 4,4 $\mu \mathrm{mol}$ de reguladores no meio de cultura) e T4 (Adição de 8,8 $\mu$ mol de reguladores no meio de cultura), respectivamente.

Ao observar visualmente o desenvolvimento dos explantes, verificou-se que, embora o TDZ tenha apresentado maior desenvolvimento, o mesmo ocorreu na forma de calos, assim como nos tratamentos T2, T3 e T4 com uso de BAP (Figura 02). Já o uso de actara e tiouréia 
proporcionou um desenvolvimento dos explantes sem a formação de calos e com mudas visivelmente sadias e aptas a indução de enraizamento aos quarenta e cinco dias. O uso da tiouréia já se mostrou efetivo na quebra de dormência das gemas de muitas espécies frutíferas segundo estudos feitos por Peres (2000). Seu uso também foi avaliado por Suwunnamek (1993), estudando o efeito de Paclobutrazol, Thiourea e Pendimethalin isolados ou em combinação sobre a indução de rebentões em abacaxizeiro, verificou que a combinação de $25 \mathrm{mg} \mathrm{L}^{-1}$ de paclobutrazol com $500 \mathrm{mg} \mathrm{L}^{-1}$ de thiouréia ou $375 \mathrm{mg} \mathrm{L}^{-1}$ de pendimethalin produziu mais rebentões do que isoladamente, tanto a 25 quanto a $50 \mathrm{mg} \mathrm{L}^{-1}$ de concentração.

FIGURA 02- Imagens referentes aos tratamentos com aplicação de BAP, TDZ, Actara e Tiouréia em $C$. citriodora in vitro, aos 45 dias após instalação

FIGURE 02- Images related to treatment with application of BAP, TDZ, Actara and Thiourea in C. citriodora in vitro, 45 days after installation

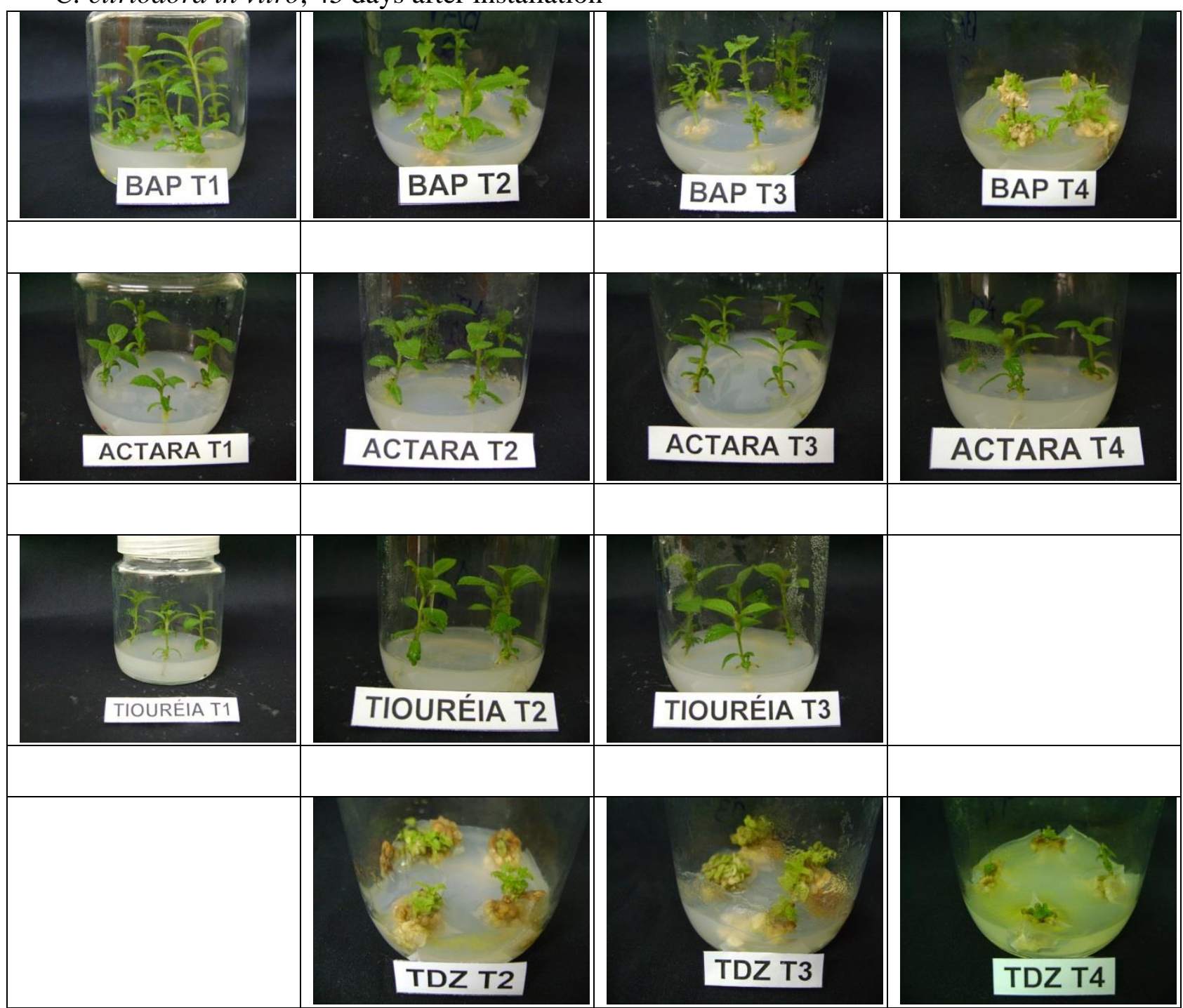

* T1 (Adição de 1,1 $\mu$ mol de regulador no meio de cultura); T2 (Adição de 2,2 T $\mu$ mol de reguladores no meio de cultura); T3 (Adição de 4,4 $\mu \mathrm{mol}$ de reguladores no meio de cultura) e T4 (Adição de 8,8 $\mu$ mol de reguladores no meio de cultura), respectivamente. 
A adição de BAP e TDZ nas concentrações de 2,2, 4,4 e 8,8 $\mu$ mol de reguladores no meio de cultura, proporcionaram a formação de calos. Os explantes do tratamento T1 com uso de TDZ ao final dos 45 dias estavam totalmente dizimados. Isto pode ser explicado pelo motivo de o meio de cultura JADS apresentar pouco $\mathrm{N}$ e, o $C$. citriodora ser exigente em nutrientes para seu estabelecimento, acarretando na perda dos explantes durante o período de avaliação.

Resultados divergentes com relação ao uso de BAP e a indução de calos foram encontrados por Nogueira et al. (2007) em estudos com Byrsonima intermedia A. Juss. Segundo os autores, a citocinina (BAP) presente no meio nutritivo, juntamente com a citocinina endógena do segmento foliar elevam a concentração deste regulador em relação à auxina, ocasionando uma diminuição na formação de calos.

Estudos feitos por Lu (1993), em relação ao uso de TDZ e a emissão de calos, corroboram com os resultados encontrados neste experimento. Segundo o autor, o TDZ estimula a divisão celular e, consequentemente, o crescimento de calos dependentes de citocininas em algumas espécies. Resultados semelhantes foram encontrados por Laszloffy et al. (1992), onde afirma que o uso do BAP em concentrações acima de 3,1 $\mu$ mol, pode aumentar a formação de calos e o rosetamento das brotações.

Os meios de cultura com uso de Actara e Tiouréia não apresentaram diferenças visíveis. Mesmo com uma TCR menor em relação aos demais reguladores testados, estes apresentaram explantes aptos à indução de enraizamento para posterior aclimatação e plantio ex vitro. Tais resultados permitem ressaltar a importância deste estudo, uma vez que se pode traçar duas linhas de estudo a partir da escolha do regulador. A primeira linha é a produção de explantes com uso de reguladores como actara e tiouréia, onde o material vegetal se encontra apto para o enraizamento e produção de mudas.

A segunda linha é a utilização de BAP e TDZ para a produção de calos para trabalhos de propagação in vitro, uma vez que os calos possuem a capacidade de se diferenciar em tecidos, órgãos e até embriões, regenerando plantas inteiras (PIERIK, 1990; TORRES; CALDAS, 1990). Segundo Rocha e Quoirin (2004), a calogênese é um processo importante para a obtenção indireta de plantas. Os calos podem conter células ou grupos de células que possuem centros ativos de divisão celular. Em condições adequadas, esses centros são induzidos e se capacitam para produção de órgãos; em alguns casos nos quais já são capazes, os centros são apenas estimulados. Tais induções ocorrem muitas vezes pelo suprimento exógeno de reguladores de crescimento, sendo que a necessidade do regulador, no que diz respeito ao tipo, concentração, relação auxina/citocinina, depende do genótipo e conteúdo endógeno de hormônio (VIETEZ; SAN JOSÉ, 1996). 
Avaliou-se também, os valores médios de peso fresco e seco e a percentagem de matéria seca aos quarenta e cinco dias pós-implantação (Figura 03).

FIGURA 03- Valores médios para peso fresco e peso seco inicial e final (em gramas) para explantes de $C$. citriodora submetidos à adição de reguladores nas concentrações de 1,1, 2,2, 4,4 e $8,8 \mu \mathrm{mol}$, aos quarenta e cinco dias após instalação

FIGURE 03- Mean values for fresh weight and initial and final dry weight (grams) to explants of C. citriodora subjected to addition of plant hormones at concentrations of 1,1, 2,2, 4,4 and 8,8 $\mu \mathrm{mol}$, the forty-five days after installation

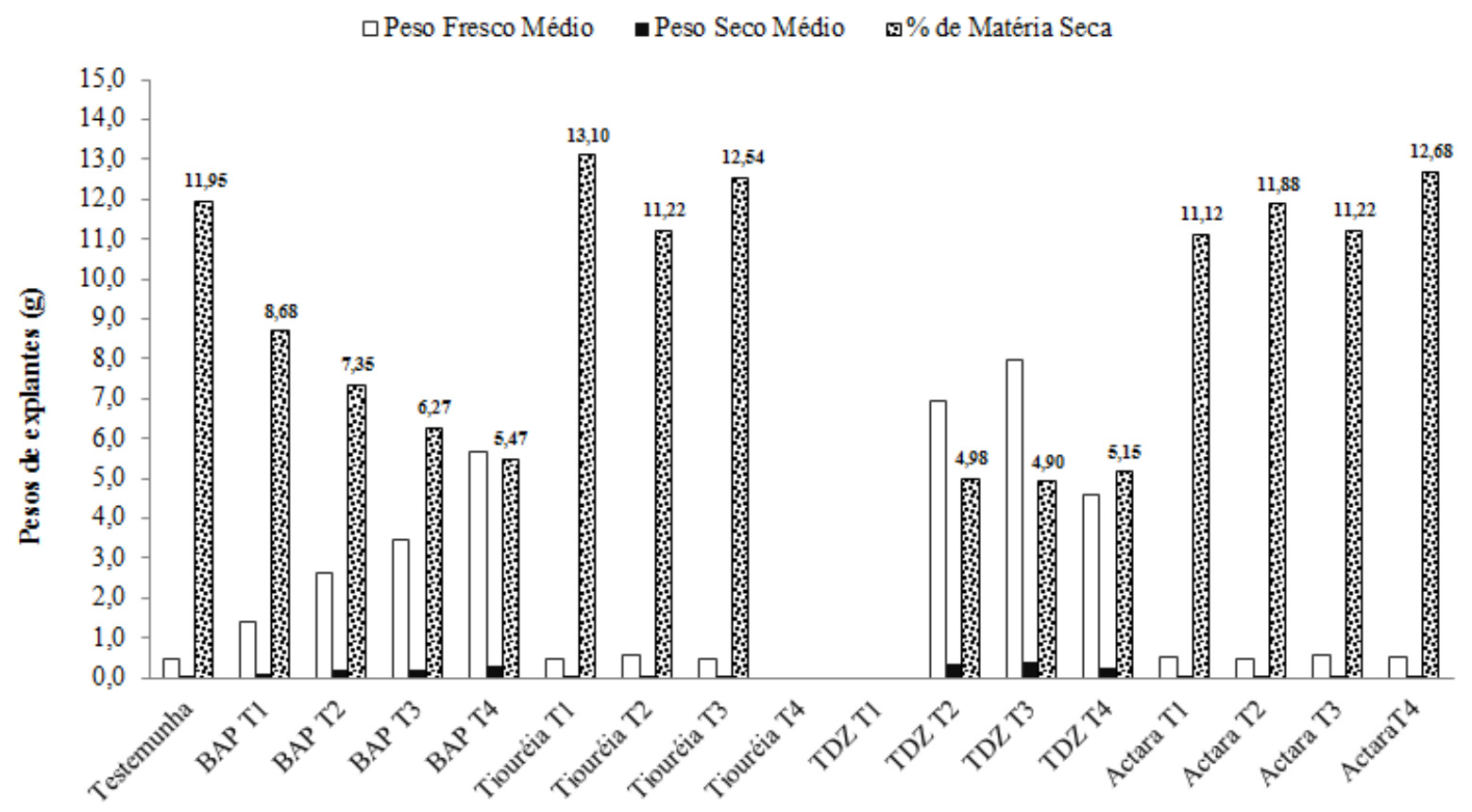

Reguladores sinteticos avaliados

\begin{abstract}
* T1 (Adição de 1,1 $\mu$ mol de regulador no meio de cultura); T2 (Adição de 2,2 T $\mu$ mol de reguladores no meio de cultura); T3 (Adição de 4,4 $\mu$ mol de reguladores no meio de cultura) e T4 (Adição de 8,8 $\mu$ mol de reguladores no meio de cultura), respectivamente.
\end{abstract}

Corroborando com o verificado na Figura 02, constatou-se que a maior percentagem de matéria seca foi observada nos tratamentos com tiouréa e actara, seguidos pela testemunha. Os valores giraram em torno de 11 a 13\% de matéria seca enquanto que nos tratamentos com BAP e TDZ, a percentagem máxima de matéria seca foi de 8,68 e 5,15\%, respectivamente. Os teores de matéria seca refletem a quantidade de material que realmente está ativo e a percentagem de água presente no material. No entanto, estes dois reguladores sintéticos, apresentaram as menores quantidades médias de peso fresco e seco em relação aos demais reguladores.

Quando avaliado o desenvolvimento dos explantes em relação aos pesos médios frescos e secos, verificou-se que os tratamentos com adição de TDZ apresentaram maior peso do que os verificados com a adição de BAP no meio de cultura. Tais resultados também foram verificados por Tabrett e Hammatt (1992). Após comparação com TDZ e BAP, os autores verificaram que o 
TDZ, ao invés do BAP, aumentou o peso fresco das culturas e a proporção de embriões derivados de epicótilos que produziram brotações adventícias de Fraxinus excelsior. O mesmo foi verificado por Hammatt e Grant (1997) em estudos com Prunus avium L e por Escalettes e Dosba (1993), em estudos com brotações adventícias oriundas de folhas de Prunus spp.. Tais autores constataram que a micropropagação foi melhor sucedida quando o TDZ foi suplementado no meio de cultura do que na sua ausência.

A formação das brotações de Fraxinus americana foi induzida em meio contendo TDZ, mas não em explantes cultivados em meio com BAP ou 2-iP (isopenteniladenina) (BATES et al.,1992). A combinação de TDZ com a zeatina, no entanto, foi o melhor tratamento para a sobrevivência e desenvolvimento de gemas advindas de epicótilos e embriões zigóticos de Picea glauca (ELLIS et al., 1991).

Por ser o TDZ mais potente que outras citocininas, as concentrações requeridas são menores que das demais citocininas para se obter resultados similares de multiplicação. Sankhla et al. (1996) verificaram que o TDZ, utilizado em baixas concentrações, foi altamente eficiente em promover a multiplicação de brotações de Albizzia julibrissin, sendo necessárias altas concentrações de benziladenina e zeatina para produzir efeito similar.

\section{CONCLUSÃO}

Quando o objetivo é a indução de calos o recomendável é a utilização de TDZ nas dosagens de 2,2 e 4,4 $\mu$ mol. $\mathrm{L}^{-1}$ no meio de cultura por apresentar maior TCR e maiores valores médios de peso fresco e seco.

Porém quando queremos o alongamento e posterior enraizamento com produção de mudas, recomenda-se o uso tanto de actara quanto de tiouréia pelo fato de apresentarem maior percentual de matéria seca e por inibir a calogênese.

\section{REFERÊNCIAS}

ADKINS, S.W.; SIMPSON, G.M.; NAYLOR, J. M. The physiological basis of seed dormancy in Avena fatua. III. Action of nitrogenous compounds. Physiologia Plantarum. v.60, p.227-233, 1984.

ASSIS, T.F.; HIGA, A.R.; ROSA, O.P.; BAUER, J.F. Propagação vegetativa da acácia-negra (Acacia mearnsii). In: Congresso Florestal Anamericano, 7; Congresso Florestal Brasileiro,1; 1993; Curitiba, Anais... Curitiba: SBS/SBEF; 1993. p. 150-152.

BHOJWANI, S.S.; RAZDAN, M.K. Plant Tissue Culture: theory and practice, a revised edition. Usevier; 1996. 
CALDAS, L.S.; HARIDASAN, P.; FERREIRA, M.E. Meios nutritivos. In: Torres AC, Caldas LS (ed.) Técnicas e aplicações da cultura de tecidos de plantas. Brasília:

ABCTP/EMBRAPA-CNPH; 1990. p. 37-70.

CARDIM, D.C. Crescimento e desenvolvimento de brotações de progênies de Eucalyptus grandis in vitro [Tese]. Piracicaba: ESALQ, Universidade de São Paulo; 2006.

CORREIA, D. Crescimento e desenvolvimento de gemas na multiplicação de Eucalyptus spp. in vitro em meio de cultura líquido e sólido [Tese]. Piracicaba: ESALQ, Universidade de São Paulo; 1993.

CORREIA D. Macronutrientes, aspectos nutricionais e bioquímicos no crescimento de brotações de Eucalyptus grandis in vitro [Tese]. Piracicaba: ESALQ, Universidade São Paulo; 2006.

DAQUINTA, M.; RAMOS, L.; CAPOTE, I.; LEZCANO, Y.; RODRÍGUEZ, R.; ESCALONA, M. Mofogénesis in vitro de Teca (Tectona grandis L.). Invest. Agr.: Sist. Recur. For. v. 11, n.1, p. 137-144, 2002.

DELATORRE, C.A.; BARROS, R.S.; VIEIRA, H.D. Germinação de sementes de Stylosanthes humilis em resposta a tiouréia. Revista Brasileira de Fisiologia Vegetal. v. 9, n.1, p. 49-53, 1997..

DINIZ, J.D.N.; GONÇALVES, N.A.; HERNANDEZ, F.F.F.; TORRES, A.C. Absorção de macronutrientes por explantes de bananeira in vitro. Pesq. agropec. bras.: Fruticultura. v.34, n.7, p. 1201-1209, 1999.

DUPUY, B.; VERHAEGEN, D. Le teck de platation Tectona grandis en Cote-d'Ivoire. Bois et Forests des Tropiques. v.235, p. 9-24, 1993.

GRAÇA, M.E.C.; KALIL FILHO, A.N.; MEDEIROS, A.C.S.; TAVARES, F.R. Efeitos das citocininas benzilamino purina e thidiazuron, na multiplicação "in vitro" de Brotações de Eucalyptus dunnii maid. Boletim de Pesquisa Florestal. v.43, p.107-112, 2001.

GOH, D.K.S.; GALIANA, A. Vegetative propagation of teak. JIRCAS Working report v.16, p. 35-44, 2000.

GOH, D.K.S.; MONTEUUIS, O. Vegetative propagation of teak. Disponível em: http://www.itto.int. Acesso em 2018.

NACHTIGAL, J.C.; ROBERTO, S.R. Poda e quebra de dormência. Site: http://sistemasdeproducao.cnptia.embrapa.br/FontesHTML/Uva/MesaNorteParana/poda.htm. Acesso em 28 set. 2018.

HERNANDEZ-NISTAL, J.; ALDASORO, J.; RODRIGUEZ, D.; MATILLA, A.; NICOLAS, B. Effect of thiourea on the ionic content and dark fixation of $\mathrm{CO}_{2}$ in embryonic axes of Cicer arietinum seeds. Physiologia Plantarum. v.57, p.256-278, 1983.

HIGASHI, E.M.; GONÇALVES, A.N. Omissão dos nutrientes minerais na produção de matéria seca, aspectos nutricionais e bioquímicos em Eucalyptus grandis Hill (Ex Maiden) cultivado in vitro. Piracicaba: Esalq/USP; 2006. 
HINOJOSA, G.F. Auxinas. In: Cid LPB (Ed.). Introdução aos hormônios vegetais. Brasília: Embrapa Recursos Genéticos e Biotecnologia; 2000.

HONG, S.O. Vegetative propagation of plant material for seed orchards with special reference to graft - Incompatibility Problems. Forestry Communication Bulletin. v.54, p.38-48, 1975.

HUANG, F.H.; AL-KHAYRI, J.M.; GBUR, E.E. Micropropagation of Acacia mearnsii. In Vitro. Cell Development of Biology. v.30, p.70-74, 1993.

HUNT, R. Concepts in plant gowth analysis. In: Edward Arnold (ed). Plant Growth Curves The Functional Approach To Plant Growth Analysis, 1982. P. 14-46.

KAOSA-ARD, A. Teak, Tectona grandis Linn. F.: Nursery techniques, with special reference to Thailand. Danida Forest Seed Center: Seed leaflet; 1986.

KAOSA-ARD, A.; SIANGTHO, V.; KJAER, E.D. Experience from Tree Improvement of Teak (Tectona grandis) in Thailand. Technical Note Danida Forest Seed Centre 1998; 50: 1-8.

LASZLOFFY, K.; KADER, A.M.A.; MATHE, A. In vitro propagation of 'Julyred' apple. Acta Horticulturae. v.300, p. 149-154, 1993.

LU C. The use of thidiazuron in tissue cultures. In Vitro, Cellular and Developmental Biology Plant. V.29, p. 92-96, 1993.

MAYER, A.M.E.; POLJAKOFF-MAYBER, A. The germination of seeds. $4^{\mathrm{a}}$ ed. Oxford: Pergamon Press, 1984.

MIRANDA, C.S. Cultura da teca (Tectona grandis) e Gmelina arborea. In: Trabalho apresentado à disciplina de culturas florestais ESALQ/USP; Piracicaba. São Paulo; 1988. p. 6.

MOK, M.C. et al. Cytokinin activity of N-phenyl-N'-1,2,3-thiadiazol-5-ylurea (Thidiazuron). Phytochemistry v.21, n.7, p.1509-1511, 1982.

MONTEUUIS, O.; VALLAURI, D.; POUPARD, C.; HAZARD, L.; YUSOF, Y.; LATIF, W.A.; GARCIA, C.; CHAUVIERE, M. Propagation clonale de tecks matures part bouturage horticole. Bois et Forets des Tropiques. v.243, p. 25-39, 1995.

MONTEUUIS, O.; BOM, M.C.; GOH, D.K.S. Teak propagation by in vitro culture. Bois et Forets des Tropiques. v.2, n.256, p. 43-53, 1998.

MURASHIGE, T.; SKOOG, F.A. A revised medium for a rapid growth and bioassay with tobacco tissue culture. Phisiologia Plantarum. v.3, n.15, p.473-97, 1962.

NACHTIGAL, J.C.; ROBERTO, S.R. Poda e quebra de dormência. Site: http://sistemasdeproducao.cnptia.embrapa.br/FontesHTML/Uva/MesaNorteParana/poda.htm. Acesso em 28 set. 2018.

NAUTIYAL, S.; RAWAT, M.S. Macropropagation of Teak (Tectona Grandis L. F.). Indian Forester, 1994, 147-151. 
NOGUEIRA, R.C.; PAIVA, R.; OLIVEIRA, L.M.; SOARES, G.A.; SOARES, F.P.; CASTRO, A.H.F.; PAIVA, P.D.O. Indução de calos em explantes foliares de Murici-pequeno (Byrsonima intermedia A. Juss.). Ciência Agrotécnica. v.31, n.2, p. 366-370, 2007.

PIERIK, R.L.M. Cultivo in vitro de las plantas superiores. [S.l.]: Martins Nijoff Publishers; 1990.

ROCHA, I.C.; QUOIRIN, M. Calogênese e rizogênese em explantes de mogno (Swietenia macrophylla king) cultivados in vitro. Ciência Florestal. v.14, n.1, p. 91-101, 2004.

SAS Institute Inc. 2002-2003. Statistical analysis system. Release 9.1. (Software). Cary. USA.

SUWUNNAMEK U. Effect of paclobutrazol, thiourea, and pendimethalin alone or in combination on the induction of suckering in pineapple. Acta Horticulturae. v.334, p. 247-254, 1993.

TIWARI, S.K.; TIWARI, K.P.; SIRIL, E.A. An improved micropropagation protocol for teak. Plant Cell. Tissue and Organ Culture. v.71, p. 1-6, 2002.

TORRES, A.C.; CALDAS, L.S. Técnicas e aplicações da cultura de tecidos de plantas. Brasília: EMBRAPA-CNPH; 1990.

VEIT, L.F. Teca, apreciada desde a antiguidade. Silvicultura. v.12, n.46, p. 30-32, 1992.

VEIT, L.F. Teca: uma visão geral. Revista da Madeira. v.5, n.30, p. 24-26, 1996.

VIEIRA, H.V.; MARTINS, E.P.; PEQUENO, P.L.L.; LOCATELLI, M. Aspectos Silviculturais da Teca (Tectona Grandis L.) em Rondônia. Rondônia: EMBRAPA-CPAF, 2002.

VIETEZ, AM, SAN JOSÉ, M.C. Adventitious shoot regeneration from Fagus sylvatica leaf explants in vitro. In Vitro Cellular Development Biology. v.32, p. 140-147, 1996. 